
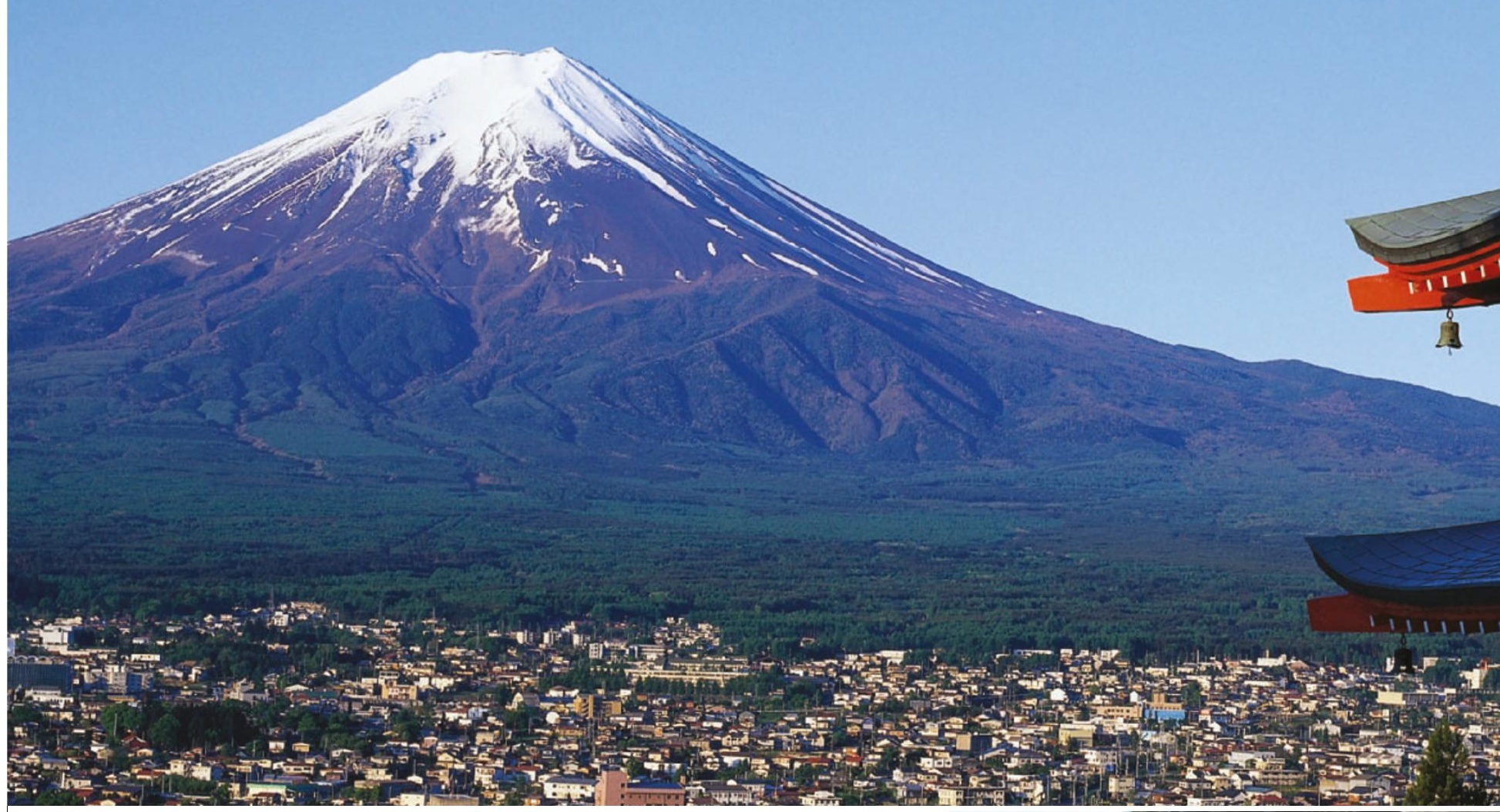

\title{
A sleeping giant stirs
}

\author{
Mount Fuji is a cultural icon and Japan's most \\ important geological feature. Yet until it began \\ rumbling a few years ago, scientists had almost \\ completely ignored it, says David Cyranoski. \\ Is it preparing to erupt again?
}

$\mathrm{M}$ ount Fuji, Japan's tallest peak, last blew its top on 16 December 1707. It spewed for two weeks or more, raining down five centimetres of hot ash on the capital city Edo - now known as Tokyo - 100 kilometres to the east. In the countryside, ash filled the riverbeds, causing decades of frequent floods.

Today, such violence is rarely associated with Fuji. "Most people seem to think it is completely dead," says Toshitsugu Fujii, director of the Volcano Research Center at the University of Tokyo. A sacred mountain by tradition, it is the legendary home of numerous deities, and thousands of pilgrims still climb to the summit each year. Even the less religiously inclined compete for offices and apartments with a view of the mountain — visible from downtown Tokyo on clear winter days. "Everyone thinks it's pretty," says Masato Koyama, a geologist at Shizuoka University, about 40 kilometres southwest of the volcano. "They won't believe it can explode until it does."

But rumblings detected deep beneath Fuji four years ago reminded people that this giant is only asleep. Concerned that an eruption might be in the offing, the Japanese government launched a concerted effort to study Fuji and learn when and how forcefully it could erupt again. Although the initial results seem to have produced more questions than answers, Earth scientists who once considered Fuji scientifically uninteresting now believe that it holds unexpected clues to the way volcanoes work.

\section{A whole lot of shaking}

In October 2000, Mount Fuji started experiencing waves of mild earthquakes more than 10 kilometres underground. They continued for about eight months. At their peak in April 2001, more than 100 earthquakes were recorded in one month, according to the National Research Institute for Earth Science and Disaster Prevention (NIED) in Tsukuba, vastly more than the average of 15 per year in the previous two decades. Although the quakes could not be felt at the surface, they carried a worrying message: the magma under Fuji is on the move.

If that movement portends an eruption, the consequences could be dire. "Nowhere in the world is a large capital city so close to a huge volcano," says Koyama. At the veryleast, dust and ash would bring Tokyo to a halt by

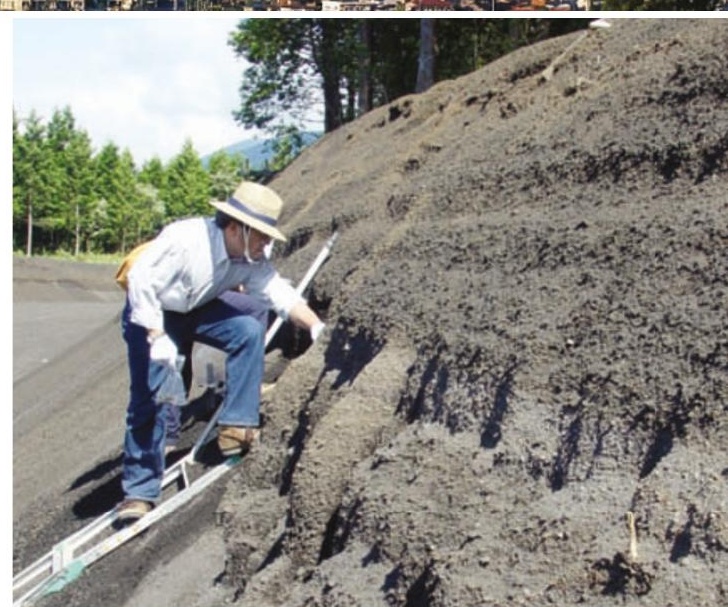

Digging into the past: with Mount Fuji (top) showing signs of waking up, scientists led by Toshitsugu Fujii (above) are rushing to gain a deeper understanding of the volcano by examining deposits from previous eruptions.

stopping traffic, grounding planes and even corrupting computer hard drives. But if the eruption came during summer, it could be much worse. Each year, 20 million people visit the golf resorts, amusement parks and summer homes that dot the volcano's flanks. Even more worrying is new evidence that Fuji has at times produced deadly pyroclastic flows - hot surges of gas, ash and rock that can travel at up to 150 kilometres per hour. Depending on the size of the eruption, these can cover distances from several kilometres up to more than a 100 kilometres.

In November 2001, the prospect of an eruption caused the Japanese government to act. It launched a $¥ 500$-million (US\$4.5-million), three-year national project to develop a basic scientific understanding of Fuji. It also allocated a similar amount of money for the development of a 'hazard map' to detail 
volcanic rock known as basalt. Volcanoes of this type usually do not explode violently because, the theory goes, basalt flows freely and does not trap gas inside.

Fuji's explosive Hoei eruption seems to be an exception and so poses a challenge to the theory, says Yoshiaki Ida, a volcanic geophysicist at Himeji Institute of Technology in the western part of Honshu. "Perhaps the equation of low viscosity with non-explosiveness is mistaken," Ida suggests.

The Hoei eruption was strange in other ways, according to evidence from 300-yearold diaries. To most modern Japanese, the handwriting from that period is almost indecipherable, but Koyama, an amateur historian as well as a geologist, found historians who could make sense of the documents. He has pored over some 30 diaries that describe important features of the eruption, which lasted more than two weeks and was interrupted by a number of lulls. Mysteriously, the intensity of the eruption seems to have picked up in the last few days when it would have been expected to level off, says Koyama. "We need a mechanism concerning the magma that can explain this," he says.

various eruption scenarios.

Despite the volcano's fame, very little hard data on it existed, so scientists had to start virtually from scratch, as if the 3,776metre peak had just been discovered. One reason for the dearth of information may be limited access to the mountain. The treacherous snowbound peak is off limits in winter, and the red-tape involved in getting samples out of the national park where Fuji is located is also forbidding.

But the other reason is scientific. "From a magma perspective I didn't find it very interesting," says Fujii. People who study magma tend to seek out purer sources, such as mid-ocean ridges, where the material comes straight from Earth's mantle, he explains. Fuji's magma, on the other hand, comes through a messy juncture where one tectonic plate bends under another, Fujii explains. "It's the dregs."

\section{Core duties}

Despite such reservations, Fujii leapt at the chance to lead the national Fuji research project, and within weeks he was drilling into the mountainside. The core samples taken from these 100- and 600-metre holes on the northeast slope are now being analysed. They should reveal in detail what sort of material erupted from the volcano in 1707, which in turn should help scientists to understand what caused that eruption. "To know what's going on today, we need to know what has happened in the past," Fujii says.

The evidence so far suggests that the 1707 eruption, known as Hoei for the period in which it occurred, does not fit neatly with standard models of volcanism. Records show that it was a particularly violent event. But Fuji consists almost entirely of a type of

\section{Emergency planning}

Meanwhile, the Sabo Technical Center, a semi-governmental institute based in Tokyo, is drawing up the hazard map. This will show in detail the most likely eruption scenarios: how much ash, lava and gas would be released; how long the eruption would last; and what the impact would be on the surrounding region. An accurate map depends in part on knowing what kind of emissions Fuji is likely to produce, so the Sabo team has been examining material from previous eruptions on Fuji's flanks.

What they have found has "The evidence so surprised geologists. Previously, far suggests that the evidence of 4,000-year-old pyro- violent eruption in 1707 clastic flows had been found at does not fit neatly with two sites around Fuji, but those standard models of were thought to be a fluke of volcanism." some kind. Basaltic volcanoes usually do not have pyroclastic flows. In 2001, however, Sabo surveyors dug up pyroclastic material at a different site. Initial estimates dated it to about 1,400 years old. “The find suggests that pyroclastic flows could be more common than previously thought," says map projectleader Nobuo Anyoji.

The map-makers also need to know where the magma is, how it is moving and what forces act on it. But the nature of Fuji's magma chambers is proving elusive. In an effort to pin them down, Hidefumi Watanabe, Fujii's colleague at the Volcano Research Center, is leading the effort to monitor the volcano's seismic movements. Shock waves from quakes work almost like an underground sonar to produce an image of the size, position and movement of magma chambers. The greater the number of sen- sors, the better that image will be. So Watanabe's team has nearly doubled the number of seismometers on the mountain's flanks to about 80 , and placed three of them deep in the holes bored by Fujii to get a better signalto-noise ratio than was previously available.

Once the arrangement of Fuji's magma chambers is understood, the deep lowfrequency (DLF) earthquakes Fuji recently experienced may be easier to interpret. Scientists hope this understanding will help them to forecast and plan for eruptions.

\section{Ready to rumble}

Earth movements of various kinds have served as warning signs in the past. For instance, in 1991, shallow earthquakes and land deformation triggered a mass evacuation around Mount Pinatubo in the Philippines shortly before it erupted. Seismic activity also set off alarm bells before the 2000 eruption of Mount Usu on the Japanese island of Hokkaido.

But DLF earthquakes are much less reliable. For every example of DLF tremblors preceding volcanic activity - several were detected before Pinatubo blew, for instance - there are many more where nothing happens. The result is a great deal of uncertainty over how to interpret Fuji's trembling.

"No convincing model has been proposed," says Motoo Ukawa, who heads the research project for predicting volcanic eruptions at the NIED. And the waveforms of Fuji's DLF quakes are particularly complicated, suggesting that the magma shifts causing them are complex and hard to model. The extra seismometers may help, but more time will be needed as the quake frequency has dropped back to previous low levels.

In the meantime, Fujii and his colleagues are getting ready to release their initial findings about the cores in May. Anyoji's group will also deliver the hazard map around the same time, but he says that it will be filled with more uncertainty than any he has ever worked on. "Where the eruption will take place, what kind of lava will flow, at what speed will it flow - these were all extremely difficult to predict," he says.

But if the magma that animates Fuji sounds like a force of evil, those who admire the mountain's aesthetics should give credit where credit is due. The 500 cubic kilometres of magma that Fuji has deposited on its flanks over the past 100,000 years has kept the mountain beautifully symmetrical in the face of constant erosion. Nevertheless, below the surface disaster lurks. "If the magma moves, sections would begin to collapse," says Richard Arculus, a geochemist at the Australian National University in Canberra. "It may be culturally sad, but that's the fate of all volcanoes."

David Cyranoski is Nature's Asian-Pacific correspondent. http://hakone.eri.u-tokyo.ac.jp/vrc/VRC.html 